\title{
WINE MARKET IN FRANCE: CHALLENGES FOR A WINE PRODUCER
}

\author{
Ieva Brence ${ }^{1}$, Associate professor/ Dr.sc.administr.; Ance Ozolina ${ }^{2}$ \\ ${ }_{1,2}$ RISEBA University of Applied Sciences
}

\begin{abstract}
The research is devoted to analysing wine market in France - its overall situation and consumers' habits. French wine market is based on product values and quality of the wine that the country produces. The aim of the study is to analyse the current market situation in the wine sector in France and to draw conclusions about the future development possibilities of a particular company, located in Southern France.

Study raised the following questions: 1 . How the current situation in the wine market can be characterised? 2 . Which are the most important challenges for the wine producers?

Findings show that the number of regular wine consumers in France is declining, while the numbers of rare users are increasing. The most common type of wine consumed by men is the age group 50 and above. According to the theory and the analysis of the French wine sector and the results of the survey conducted, the main determinants of the choice of purchase - namely the region and the year of production of the wine, as well as the award-winning medals were classified. The popularity and reputation of the region is an important condition for customers' choice. At the point of sale, customers believe that the label plays a crucial role in making purchases.
\end{abstract}

Key words: wine, consumption, gender differences, French market.

JEL code: Q13.

\section{Introduction}

The current situation in the French wine market is similar to that of 1973 , when the supply of wine was much higher than the demand of buyers in a rapidly changing and growing market. Marketing in the wine sector, both in France and across Europe, is still in its infancy, so it is important for industry to focus not only on product production but also on sales methods.

The aim of the study is to analyse the current market situation in the wine sector in France and to draw conclusions about the future development possibilities of a particular company. This company mainly sells products in southern Aude, France, where the winery is located. Conquering the market at national level seems to be an achievable task for the company, but at the same time there are various obstacles that are mostly related to limited resources over a given period.

The tasks of the research are: 1 . Analyse the wine and wine market. 2 . Conduct a survey of the French people's habits of buying wine; 3. Develop solutions to strengthen and improve the company's business. The subject of the study is the wine sector in France, while the subject of the study is a particular winery in the Aude region, France.

Research questions: 1. How the current situation in the wine market can be characterised? 2 . Which are the most important challenges for the wine producers?

The research involves both qualitative and quantitative methods. Theoretical analysis is accompanied by surveys, conducted at Monoprix stores, France, where 151 buyers were surveyed they responded to questions about their shopping habits and factors affecting the choice of product. The data are analysed, by using central trends. For measuring the internal consistency of the sample, Cronbach's alpha coefficient is calculated.

\section{Research results and discussion}

\section{Marketing specifics in wine industry}

The wine market consists of the retail sale of wines, champagne, fortified wine and sparkling wine. The market is valued at the retail price and includes all applicable taxes. The market volume reflects

\footnotetext{
${ }^{1}$ Corresponding author. Tel.: +371 26363506, E-mail address: ieva.brence@riseba.Iv
} 
the total amount consumed and expressed in millions of litres of wine. Any currency conversion used to form a market report uses the average exchange rate for that year (Marketline, 2015).

The wine market requires new communication and marketing skills to promote winery, "wine tourism" used as one of them. However, the tourist area is interesting for visitors from May to October - a comparatively short period for the wineries to create new jobs (Faivre, 2009). Region plays a comparatively big role in the wine marketing. For example, selling a Cote de Province wine sells the image of the region, as well as a combination of quality grapes. Consequently, the tourism industry and wine makers are closely linked (Faivre, 2009).

When a company decides to look for the most appropriate customer group to sell, they choose a particular market segment and then adjust the marketing mix. Market segmentation in the wine sector helps to group products at their price rather than choosing a target market or marketing strategy to develop (Castaing, 2013). Wine knowledge types are a significant predictor of variety seeking purchasing behaviour of wine. Wine consumers who think they know a lot about wine, tend to engage in more variety seeking behaviour in their wine purchasing. This suggests that marketers should adapt their segmentation, targeting and channel strategies to individual knowledge types to be more successful (Debbie, Frauke, 2018).

For a better understanding of buyers and their requirements, the authors Rouzet and Seguin offer to divide buyers into several categories: 1 . Non-consignee: $25 \%$, mostly women under 25 , buyers with medium to low income that choose other drinks. Representatives of this category often say they don't like or don't like wine for some specific reason (France Agri Mer, 2014); 2. Rare users (fr: occasionnems peu impliqués): $20 \%$, most often women under the age of 45 who love the taste of wine, but still prefer other drinks. Representatives come from the highest social category, choose wine for festive occasions, but the product is not interesting to them. Consumers acknowledge not to have in-depth knowledge of wine but use it for festive occasions (France Agri Mer, 2014); 3. Rare users of tradition (fr: occasionnels for tradition): $18 \%$, the members of this group pay little attention to the product, the group is represented by men from the age of 56 who enjoy wine, they represent a lower social level. These consumers consume wine because they are traditionally cultivated, cultivated with wine, but at the same time have No in-depth knowledge of the products (Rouzet, Seguin, 2012); 4. Daily users (inconditionnels quotidiens): $16 \%$, this category mostly consists of men aged 45 and over. Wine is an integral part of their diet, it is perceived as a meal at a meal rather than as an enjoyable, tasty drink. This category is represented by the lower level of society (France Agri Mer, 2014); 5. Interested users (occassionnels hédonistes impliques): $21 \%$, category strongly represented by men aged 36-55. Regular wine users interested in products and culture, traditions that enjoy product offerings. The category is mostly represented by the highest level of society, which often makes a personal collection (Rouzet, Seguin, 2012). McGarry, Lindsey, et.al. through statistical tests and a binary probit model, results suggest significant differences between generations and an apparent need for distinctly different marketing strategies when targeting one generation compared to the other. Heavy spenders tend to be male, Baby Boomers, use magazines for information about wine and are wine enthusiast (McGarry, Lindsey, et.al., 2018). The realization of wine products and the conceptual approach to selecting products to market products and attracting customers are becoming increasingly complex. For customers, wine marketing is mostly related to the characteristics of packaging and the services offered. On a general level, wine is considered to be a beverage in a bottle coming from a variety of grape varieties, and depending on the technique used in the ripening process, which has certain characteristics such as aromas, degree strength, age 
and taste. Each buyer has its own individual perception of colour, taste and aroma, so the opinion of the same product may differ, which will allow it to decide whether the product is pleasant and whether it will be purchased (Westling, 2001). Apart from the hidden wisdom of local technology, the great considerations are on the quality control of the local production. The safety becomes a very big issue and this is also a legal issue in quality control (Wiwanitkit, 2019).

Product: $80 \%$ of the wine purchased in supermarkets is directly determined by the visual aspect of the bottle, without regarding the label. Customers have different bottle shapes, colours and designs associated with a particular region of France and their wines (Westling, 2001). At the same time, wine bottles have become a common use. For example, in the Bordeaux wine bottle (fr: bordolaise) you can also find wines from other regions, which creates a relatively important recognition problem for customers. Choosing a bottle is an important condition, even more in supermarkets where there are No specialists to advise and recommend wines to their customers. Most often the winery chooses bottles, taking into account traditions rather than marketing strategies. For example, the finer and longer it will be, the client will find it more elegant, modern and dynamic - this type is more suited to women's choice (Rouzet, Seguin, 2012). Wine labels in France are strictly regulated. Label layouts are controlled by the DDCCRF (a directorate that controls potential competition and consumer protection, eliminates the risk of fraud). Wine etiquette is an important mean of communication and must contain mandatory information. The wineries are free to choose the shape, colour and quality of the paper according to their target market. The quality of the paper is very important, for example, how well it fits or fades from the bottle, which indicates the quality of the product. Also used is a printing technique that increases the level of the product, whether the text is written with power (gives a metallic effect) rather than a simple ink (Rouzet, Seguin, 2012).

Price: Following the fact that wine is not a basic product, pricing the product is an important process. The three most important factors for pricing are demand, competition and revenue from sales. Price sensitivity depends on the price a customer is willing to pay for a particular product. Given that wine is not a primary product, buyers associate higher-priced products with better quality. The price of wine products depends on the distribution channel (Rouzet, Seguin, 2012).

Promotion: Communication in the wine sector is the most important element of the marketing mix. Communication at a global level creates a product image that promotes further demand. Product promotion takes place through a variety of networks where different marketing operations are carried out: direct contact with customers; Internet; media; direct marketing, advertising, public relations, sponsorship; participation in various events; distribution channels (Jitareanu, 2012).

A relatively new and potential wine distribution channel is offering products on websites. Wineries (or a group of multi-breweries) create their own website offering the products at a higher price. Online stores allow customers to provide complete product information, tasting advice, and information on the winery (Curbertafond, 2015).

Brand: The brand makes it possible for the customer to recognize the particular product and manufacturer. It includes various symbols and contains information to encourage buyers. The brand must be easy to remember and internationally recognizable. In the wine sector, the brand is not changed frequently (at least 10 years), as its promotion is a long-term measure. In wine sector the brand is most often associated with the name of the wine-maker or their ancestors, the name of the vineyard or the name of the brewery. All brands must be protected in France, so they are registered by the INPI Institute. When choosing a brand of wine products, one has to take into account the fact 
that it has to be in line with the target market and the desired position in it, according to the marketing strategy (Thomas, Painbeni, Barton, 2013).

Services: The availability of different services in the winery, as visits to the brewery tourists, tastings, etc. are at the core of the brand differentiation strategy and are used in communication (Vinotrip, 2017).

Rouzet and Seguin in their study explain this with: a new category of buyers buying wine with a view to tasting it during festive or special events; professional buyers who are familiar with the products and their specific features, strengths and weaknesses; an increasing supply of wines, which is not clear to buyers, so wine experts are forced to provide more complete product information (Rouzet, Seguin, 2012). In wineries, customers are admitted to a specially designed room for product presentation and tasting. The wine sales process consists of 6 phases: 1) reception, 2) winery presentation, 3) customer needs determination; 4) argumentation, presentation and tasting of different wines, 5) answers to customer questions, comments, criticism, 6) conclusion (Rouzet, Seguin, 2012).

In study, C.Hall and R.Mitchell distinguish the following groups of tourists participating in wine tastings: - wine lovers, who are very interested in products, often go to wineries, wine is a kind of hobby;

- wine interested, who have great interest in wines, sometimes visit the winery; - curious tourists interested in seeing the region, getting to know the culture, regardless of wineries, are a form of entertainment. Representatives of this group have No in-depth knowledge of wines. (Hall, Mitchell, 2008)

Cafes, Restaurants, Hotels: In collaboration with independent restaurants and hotels, wine producers are interested in long-term cooperation. These market segments are attractive due to distance and logistics organization, as well as the desire of restaurants to offer their customers local products. Unlike the "chain" companies, independent business representatives who decide on a product are a chef, a restaurant vineyard or a company director (Rouzet, Seguin, 2012).

Corporate Committees: It is the responsibility of the Business Committees to develop social activities and support companies with more than 50 employees. The Committee can be seen as an intermediary that allows service providers to offer their products - wine with "discount" (advantage) prices. The sales process for this channel is atypical, as the process begins with contact creation, product presentation, tasting, and later an agreement on a particular "service" - that the company is interested in cooperating with the manufacturer, such as participating in open days, cataloging, gift sets, etc. If the manufacturer wants to cooperate with the company's committees, bargaining the price will take time and (Rouzet, Seguin, 2012).

Wholesaling in wine purchases takes place through 'central' vineyards, with the aim of eliminating large numbers of intermediaries and reducing costs. "Centers" collaborate with manufacturers and accordingly negotiate purchase prices. Collaboration with wholesale hubs consists of the following stages: wholesale network selection (national, regional or local); product tests; price agreement, bargaining; contract signing; receiving a supplier code (Curbertafond, 2015).

Exhibitions: Participation in various exhibitions has become an integral part of winery communication. Before registering, the company has to evaluate the region, the potential market and the interest of the customers depending on the exhibition in which it wants to participate, as the one-off participation will not provide feedback in the long term (Curbertafond, 2015). 
Opinion leaders are important to the wine marketer, for their influence on other wine consumers, which is considerable. As part of their marketing strategies, wine marketers might want to give careful attention to the identification of opinion leaders-and the scales employed here might be useful in these efforts-in order to persuade them to lead other consumers to their target wine brands (Vigar-Ellisa, Pittcand, Caruanad, 2015). The pairing of wine with music goes back a long way, starting out with commentators at first merely just using musical metaphors in order to describe the wines they were writing about. In recent years, however, this area of interest has morphed into a growing range of multisensory tasting events in which wine and music are paired deliberately in order to assess, or increasingly to illustrate, the impact of the latter on people's experience of the former. Initial isolated small-scale and often anecdotal reports of music supposedly changing the taste of wine have since evolved into large-scale experiential, experimental, events (Spence, 2019).

Taylor and Barber suggest that in addition to product characteristics, the customers' purchasing decisions may be driven by less obvious factors such as their perceptions of how others will view them and the information selected during a wine purchase situation (Taylor, Barber, 2016).

\section{Wine consumption trends in France}

In several countries, the wine sector has a relevant role in terms of employment and companies' revenues, attracting the interests of many scholars (Giacosa, 2019).

France is the largest wine producer in the world and a leader in the industry, which is characterized by the following data compiled by France Agri Mer: The total area of vineyards reaches almost 813,000 ha, producing about 41 million hectolitres of wine per year; $95 \%$ of the total production by crop is divided into 30 departments and 16 regions. 95000 farms with active activity are listed, the average size of each farm is 8 hectares. There are 250,000 jobs directly linked to wine making. More broadly, indirect jobs (bottle, packaging, etc.) in the industry and trade account for up to 800,000 employees (France Agri Mer, 2014). France is one of the world's leading wine producers, accounting for around 87,400 winemakers. In 2014, domestic production grew by $12 \%$ compared to 2013, reaching 4.6 billion litres, mainly due to the higher consumption of AOP (Appellation d'Origine Protegee) from the following regions: Cotes du Rhone, Bordeaux and Burgundy. France is also the leader in wine exports - exports to $€ 7.8$ billion in 2013, while the country is less important as an importer (Marketline, 2015).

The total revenue of the French wine market in 2014 was about $\$ 31.2$ million. Market consumption in France declined by $-1.5 \%$ between 2010 and 2014, reaching 2.8 million litres in 2014 as a whole. Taking into account the market analysis of recent years, industry analysts expect the market to drop - by the end of 2019 the amount of wine consumed will drop to 2.5 million litres (Marketline, 2015). Decreasing consumption is a long-term process. One of the reasons is the decline in the number of regular wine consumers. Comparing the data with the 1980s, when half of the population regularly consumed wine, in 2014 less than one fifth of the population consumes wine. Soft drinks such as water and fruit juices, etc. are becoming more and more popular during meals (Marketline, 2015).

French wines are an integral part of the total land area, and the wines of each region represent the features and characteristics of the region. These wine names have gained and developed their reputation with the incredible varieties offered by wine makers and regions. Each area of the area differs with the fertility of the soil and, therefore, with the uniqueness of the wines. French wines 
come from the following areas: Alsace, Beaujolais, Bordeaux, Champagne, Charentes, Corse, Jura, Languedoc, Provence, Roussillon, Savoie, Sud-ouest, Val de Loire, Vallee du Rhone (Vignevin, 2012).

The French wine culture dates back two centuries ago and has allowed different wines to be found in all regions of France. Over the years, several generations of winemakers have created and enriched their products and are still working on new wine tastes. The position of the French wines on the world markets is based on the supply of quality and unique products (Barbulescu, 2016).

Along with annual research, every 5 years since 1980, France Agrimer collects data on wine consumption in France. The latest study was conducted in October 2015. Since 1980, the proportion of regular wine consumers (using wine every day or almost every day) has decreased and this trend is continuing in 2015: half of wine consumers under the age of 35 consume wine every day, which is $16 \%$ less than the previous period. Also, the tendency of regular "casual consumption" (using wine 1-2 times a week) is decreasing, and in 2015 the average consumption of wine among the surveyed population is one or two times a week (France Agrimer, 2015).

At the same time, the new wine scenario, a consequence of the globalization of the world's wine market, has resulted in a new geographical map for wine where the number of wine consumers is constantly increasing (Bonaria, 2019). On the wine market, the purchasing behaviour derives from a certain satisfaction that corresponds to a certain motivation (Ignat, Costuleanu, Timofte, Acostachioaie, 2017).

When regular consumption of wine accounts for only $16 \%$ of consumers, the number of 'casual' consumers has increased significantly, to $51 \%$. These changes in behaviour can be explained by significant sociological changes, such as the transition from rural to urban residents. If, in the past, wine was a drink to relieve thirst for heavy agricultural work, today's consumers prefer to enjoy it outside their meals (France Agrimer, 2015). The total drop in consumption is assessed by type of wine. This mainly affects Table wines and IGP products, but at the same time the AOC category also falls slightly (Inao, 2014).

The survey conducted by France Agrimer also highlights various consumption patterns depending on the age and gender of the consumer. Survey surveys show that when comparing wine consumption between women and men, most regular wine users are men (50 \% more). To a large extent, this phenomenon is associated with specific consumption habits, for example, in France, men prefer to drink red wine during meals, while women prefer wine tasting outside meals (France Agrimer, 2015). The France Agrimer study also found that the proportion of regular users increases with age. $38 \%$ of wine is used by people over 65 (regular consumers), less than $10 \%$ - under 50 (France Agrimer, 2015).

Wine sales in the French wine market were more profiTable in 2014, with a total revenue of $\$ 21$ million, representing $65.8 \%$ of the total market value. Compared to champagne sales, its revenue was $\$ 6.1$ million in 2014, representing $18.8 \%$ of total market revenue (Marketline, 2015). Taking into account the current market performance, the volume is expected to decline even faster - by $1.6 \%$ over the five-year period 2014-2019, with a market value of $\$ 28.9$ million by the end of 2019 (Marketline, 2015) . Market Value Forecast until 2019 The French wine sector will amount to $\$ 28.8$ million, up $7.5 \%$ on the 2014 figure. The annual rate of change in the market is forecast at $1.6 \%$ (Marketline, 2015).

In order to get a better understanding of wine consumption, a survey was conducted in the Paris region, Monoprix stores in December. The Quick Tap Survey application was used for the survey. The total number of respondents was 151 . The categories of buyers can be found in Table 1. 
The groups of respondents (number of respondents - 151)

\begin{tabular}{|l|c|c|}
\hline \multicolumn{1}{|c|}{ Age groups } & Males & Females \\
\hline $\mathbf{- 3 0}$ & 16 & 11 \\
\hline $\mathbf{3 1 - 4 0}$ & 28 & 25 \\
\hline $\mathbf{4 1 - 5 0}$ & 18 & 23 \\
\hline $\mathbf{5 1 - 6 0}$ & 15 & 6 \\
\hline $\mathbf{6 1 +}$ & 7 & 2 \\
\hline
\end{tabular}

Source: author's calculations based on the survey, $n=151$

Gender groups were surveyed by gender: 84 men and 67 women. Of the total number of buyers surveyed, 45 customers found themselves to be wine connoisseurs. Given the demographic situation in France, the percentage of data results corresponds to the age group of the survey results.

\section{Demographic situation in France}

\begin{tabular}{|l|c|c|}
\hline \multicolumn{1}{|c|}{ Age groups } & Males & Females \\
\hline Less than $\mathbf{2 0}$ & $25.7 \%$ & $23 \%$ \\
\hline $\mathbf{2 0}-\mathbf{6 4}$ & $57.6 \%$ & $55.8 \%$ \\
\hline More than 65 & $16.7 \%$ & $21.2 \%$ \\
\hline
\end{tabular}

Source: author's calculations based on the survey, $n=151$

For the purpose of verifying the reliability of the internal content of the survey, the calculation of the Cronbach a coefficient for male and female groups was applied to a total of 3 different scales.

Table 3

\section{Cronbach's Alpha}

\begin{tabular}{|l|c|}
\hline \multicolumn{1}{|c|}{ The scales } & Cronbach's Alpha \\
\hline The role of the label in the product & 0.98 \\
\hline Relationship between wine types and product connectors & 0.54 \\
\hline
\end{tabular}
Source: author's calculations based on the survey, $n=151$

The 'label scale' confirms the reliability of the survey, given that the Cronbach's alpha indicator exceeds 0.6. Below the assumed confidence factor is the 'Scale of his types and products' (Cronbach $a=0.54$ ), which indicates a reduced data reliability factor. However, these values are relatively close to the confidence factor of 0.6. The purpose of the survey was to find out what the buyers' habits are and what aspects determine their choices.

Aspects influencing the purchase (number of respondents - 151)

\begin{tabular}{|l|c|}
\hline \multicolumn{1}{|c|}{ Regions } & $\mathbf{9 7}$ \\
\hline Year & 82 \\
\hline Etiquette & 52 \\
\hline Prizes & 55 \\
\hline Grape combinations & 40 \\
\hline The visibility of the dairy & 26 \\
\hline Price & 73 \\
\hline
\end{tabular}

Source: author's calculations based on the survey, $n=151$

From the data obtained it can be concluded that the most important factor for buyers in wine selection is the region from which the wine comes, as well as the year and price of the product. There are several reasons for choosing a region for buyers: The habit of buying wines from a particular region; grape combinations that determine how light / heavy the wine will be; prestige of the region, visibility; how well the particular wine will be in accordance with the intended meal. $50 \%$ of the surveyed buyers confirm that the discounts and special offers that apply to the wines are of interest 
to them, as well as the decisive factor in making the choice. In turn, $25 \%$ of the surveyed buyers said that discounts will not always be an important factor in their choice. For example, if wine is of high quality, a rare product, or otherwise "special", the price will not be the determining factor.

\section{Conclusions}

1) The marketing of the wine sector is a relatively new industry with different characteristics that must be taken into account when marketing the product, in particular the packaging of a product consisting of a large number of components, different sales channels and the potential of tourism in the wine sector competitiveness.

2) The number of regular wine consumers declined in 2015, while the number of rare users increased. The most common type of wine consumed by men is the age group 50 and above.

3) According to the theory and the analysis of the French wine sector and the results of the survey conducted, the determinants of the choice of purchase, namely the region and the year of production of the wine, as well as the award-winning medals were classified.

4) The popularity and reputation of the region is an important condition for customers' choice. For example, the Bordeaux region is very popular and offers a large number of different products that are not comparable to the Corbieres region, so it is necessary to promote and familiarize customers with the region and its products.

5) At the point of sale, customers believe that the label plays a crucial role in making purchases.

6) A large number of participants meet in the wine market, so loyalty is a crucial rule, which is the key to long-term cooperation.

7) The development of the wine sector and tourism is a new direction in wine marketing, which allows not only the marketing of wine, but also the knowledge of the region and culture, thus the promotion and involvement of tourism activities is an additional means of communication for the company. The concept of guest houses, as well as the rental of event space in wineries, has become popular with many companies.

\section{Bibliography}

1. Barbulescu, O. (2016). Industry Report. International Expansion, Market Maintenance Strategy Used by French Winemaking Industry. [article] Annals of Constantin Brancusi Univerity of Targu Jiu.

2. Bonaria Lai, M. (2019). Consumer Behavior Toward Wine Products. Case Studies in the Wine Industry. $A$ Volume in the Consumer Science and Strategic Marketing Series. Woodhead Publishing Series in Food Science, Technology and Nutrition, pp. 33-46.

3. Bouchez, A., Pihier, S., Bernadet, J.P. (2014). Precis De Marketing. Paris: Nathan.

4. Castaing, Y. (2013). Strategies et Marketing du Vin. Paris: Dunod.

5. Curbertafond, M. (2015). Entreprendre Dans le Vin. Paris: Eyrolles.

6. Debbie, E., Frauke, M. T. (2018). The Effect of Wine Knowledge Type on Variety Seeking Behavior in Wine Purchasing. Journal of Wine Research. Vol. 29 Issue 2, pp. 71-86.

7. Faivre, G. (2009). Le Marketing Identitaire du Vin. Bordeaux: Editions Féret.

8. Giacosa, R. (2019). Wine Consumption in a Certain Territory. Which Factors May Have Impact on It? Production and Management of Beverages. Volume 1: The Science of Beverages, pp. 361-380.

9. France Agri Mer (2016). Bilan des Marches a la Production 2015/2016. [pdf] Retrieved: http://www.franceagrimer.fr/Stockage-Actualites/Archives/2016/Synthese-du-bilan-2015-2016-desmarches-a-la-production-vin/(filiere)/739/(nodeActu)/745. Access: 15.06.2018.

10. Hachette Livre (2016). Le Guide Hachette des Vins 2017. Paris: Hachette.

11. Ignat, G., Costuleanu, C.L., Timofte, A-A., Acostachioaie, F. (2017). Aspects Concerning the Identity of Female Wine Buyers. Agronomy Series of Scientific Research / Lucrari Stiintifice Seria Agronomie. Vol.60 Issue 2, pp. 77-80.

12. Jitareanu, A.F. (2012). Studies on Global Trends in Wine Marketing. Agronomy Series of Scientific Research / Lucrari Stiintifice Seria Agronomie. Vol. 57 Issue 1, pp. 201-206.

13. Rouzet, E., Seguin, G. (2012). Le Marketing du Vin. Paris: Dunod. 
14. Spence, C. (2019). Multisensory Experiential Wine Marketing. Food Quality \& Preference. Vol. 71, pp. 106116.

15. Taylora, C., Barber, N. A. (2016). How Will My Wine Purchase Decision Be Viewed by Others? Journal of Wine Research. Sep2016, Vol. 27 Issue 3, pp. 202-225

16. Thomas, P (2013). Entrepreneurial Marketing Within the French Wine Industry. International Journal of Entrepreneurial Behaviour \& Research 19(2).

17. Vigar-Ellis, D; Pitt, L; Caruana, A. (2015). Does Objective and Subjective Knowledge Vary Between Opinion Leaders and Opinion Seekers? Implications for Wine Marketing. Journal of Wine Research. Vol. 26 Issue 4

18. Westling, B. (2001). Wine Marketing. Retrieved: http://www.marketingwine.com/pdfs/winemarketing101.pdf. Access: 20.02.2018.

19. Wiwanitkit, V. (2019). Alcoholic Beverage Production in Indochina: Local Wisdom, Safety, Quality, and Legal Control. Production and Management of Beverages. Volume 1: The Science of Beverages, pp. 381-407.

20.Wolf, M. McGarry; Higgins, L. M.; Wolf, M. J.; Qenani, E. (2018). Do Generations Matter for Wine Segmentation? Journal of Wine Research. Vol. 29 Issue 3, pp. 177-189. 